\title{
Entre Mitos e Magia: desvendando aspectos literários e comerciais no mundo mágico de Harry Potter
}

\author{
Ingrid dos Anjos Carvalho Soares ${ }^{1}$
}

\begin{abstract}
RESUMO: Este artigo pretende mostrar que o trabalho desenvolvido pela inglesa Joanne Kathleen Rowling ao escrever e publicar sete livros que narram a estória de um garoto chamado Harry Potter é literário e não somente produto da indústria cultural. Para tanto, foi necessário promover incursões no campo da literatura infanto-juvenil e seus componentes lúdicos, tais como a mitologia, o fantástico, as lendas, o imaginário infantil e seu papel maturador psicológico para crianças e jovens leitores, preparando-os para ingressar na vida adulta. Ao final, este trabalho mostra que as técnicas narrativas utilizadas foram vitais na arquitetura dessa trama mágica.
\end{abstract}

ABSTRACT: This article shows that the production of English Joanne Kathleen Rowling to write and publish seven books that tell the story of a boy named Harry Potter is literary, not only the product of the culture industry. Therefore, it was necessary to promote incursions in the area of children's literature and entertainment components, such as mythology, the fantastic, legends, the children's imagination and its importance is psychological maturity for children and young readers, preparing them to join the adulthood. In the end, this work shows that the narratives techniques are the most important part in the architecture of this plot magic.

PALAVRAS-CHAVE: Literatura infanto-juvenil. Mitologia. Fantástico. Imaginário. Indústria cultural. KEYWORDS: Children's literature. Mythology. Fantastic. Imaginary. Cultural industry.

\section{1) Panorama geral sobre a literatura infanto-juvenil}

No contexto da realidade pós-moderna, muito se discute sobre a questão da qualidade literária. Definir o que é ou não literatura é um trabalho complexo e árduo, pois nem todo livro lançado no mercado é considerado literário, havendo, então, critérios que devem ser observados para que uma obra possa ser reconhecida como tal.

Urge, por conseguinte, lançar um olhar mais atento à literatura infanto-juvenil, que é um ramo marginal dentro do cânone literário brasileiro. Fora do Brasil, esse ramo tem apresentado novos ícones na escrita textual para os pequenos, como por exemplo, a ficção seriada Harry Potter, da autora inglesa J. K. Rowling. Seus textos têm sido alvo de inúmeros estudos fora e, surpreendentemente, dentro de Brasil. Harry é uma

1 Graduanda de Letras Português e respectivas literaturas da Universidade de Brasília UnB. 
personagem bastante conhecida por crianças e jovens contemporâneos e muito tem se especulado acerca de sua natureza: essa saga tem ou não valor literário? Trata-se de um questionamento pertinente devido à enorme quantidade de livros vendidos e aos milhões de dólares lucrados pela autora, editoras e indústria cinematográfica através da narrativa ficcional do bruxinho mais famoso de todos os tempos.

Os livros que contam as aventuras de Harry Potter são direcionados ao público infanto-juvenil. Transformaram-se em modelo de sucesso editorial e, conseqüentemente, despertaram a desconfiança dos críticos e estudiosos nos quatro cantos do planeta. Para que se tenha uma opinião elementar, primeiramente, é preciso fazer algumas considerações acerca da literatura dedicada aos jovens e infantes para que a compreensão do universo rowlinguiano seja satisfatória.

A literatura, num aspecto geral e em poucas palavras, é uma obra de arte com elementos que a distanciam do conhecimento superficial e da cultura de massa, tendo como uma de suas características a função libertadora-social para a humanidade, resgatando e aprimorando conhecimentos, aguçando desejos individuais, ampliando a visão de mundo, o que a torna tão importante e respeitada.

Apesar de tamanha magnitude e relevância, a literatura dirigida ao público adulto, que é a mais produzida e divulgada, não pode ser lida e apreciada por todos, especificamente, por crianças. Dependendo da complexidade, os textos literários se restringem a determinado nível etário, pois os assuntos e a linguagem tornam a compreensão do jovem leitor quase impossível.

Nesse prisma, a literatura infanto-juvenil pretende proporcionar a leitura de textos de qualidade à criança e ao adolescente, tendo em vista que nessa época da vida a arte literária pode ajudar no desenvolvimento psicológico saudável e no amadurecimento necessário para adentrar a fase adulta.

Esse ramo literário não nasceu para a infância nem para a adolescência. $\mathrm{Na}$ verdade, sua origem se deu através das narrativas contadas oralmente e estas eram dirigidas a todos que estavam presenciando sua transmissão. A criança não era considerada diferente dos adultos, mas sim um deles em miniatura. A literatura infantojuvenil é um ramo da literatura ainda considerado de difícil definição. Até porque o conceito de infância como conhecemos hoje é relativamente recente, surgindo através de uma criação européia nos idos do século XVII, com acentuada participação da França e da Inglaterra. 
O estudioso Neil Postman (1999) refere-se a outra data para o surgimento do conceito de infância. Segundo ele, foi no século XV com a invenção da prensa tipográfica que se pensou pela primeira vez na criança como um ser que não era um mini adulto, e sua educação foi repensada depois da propagação dos livros em grande escala.

Ainda que num primeiro momento a conceituação de infância tenha sido formulada visando a proteção das crianças burguesas, a escolarização infantil acabou por estender, através dos anos, os direitos advindos da nobreza às crianças das mais variadas camadas sociais já no fim do século XVIII.

Ao longo dos tempos, o conceito de infância tem se transformado, rediscutido a cada momento histórico específico. Acompanhando esse processo, a literatura infantojuvenil se molda a partir das novas conceituações e também muda para se adaptar às necessidades da criança contemporânea. Nelly Novaes Coelho, em sua obra intitulada Literatura Infantil: Teoria, análise, didática (2000), afirma que esta é fenômeno de criatividade que representa o mundo, o homem, a vida, através da palavra, fundindo os sonhos e a vida prática; o imaginário e o real; os ideais e sua possível/impossível realização.

Um tema relevante dentro do tema em tela, segundo Dirce Lorimier Fernandes (2003), é o fato de que a maioria das obras direcionadas ao público pueril até o século passado eram, na verdade, adaptações de obras dirigidas aos adultos e que de algum modo caíram no gosto das crianças, como por exemplo, Aventuras de Robinson Crusoé, de Daniel Defoe, e Viagens de Gulliver, de Swift.

O escritor Bartolomeu Campos de Queirós (2005) defende que cada criança deve ser tratada individualmente, inexistindo um conceito genérico para elas. Ele não crê em receitas teóricas de como escrever para a infância, pontuando que as diferenças individuais é que determinam a preferência e o gosto de cada leitor. Por este viés, é possível compreender que a literatura infanto-juvenil é abrangente e ao mesmo tempo diretiva, uma vez que possui características próprias e público alvo definido, mas não tem receita pronta para sua produção.

Com relação ao destinatário idealizado e definido, levanta-se a questão da recepção no âmbito etário e da qualidade da obra infanto-juvenil. Como dito anteriormente, uma criança, provavelmente, não tem condições de ler um livro para adultos. Contudo, o contrário é recíproco? Não. Um adulto pode ler e assimilar a 
mensagem de uma obra literária infanto-juvenil sem dificuldades. E mais, pode gostar da temática, do enredo e das construções estéticas voltadas à infância.

No ensaio "O jogo do faz-de-conta”, Anna Cláudia Ramos (2005) aborda essa perspectiva, afirmando que:

LIJ é literatura sim, como qualquer outra. E é arte sim. Arte da palavra. Da linguagem. Do trabalho com a linguagem. Creio que a LIJ tem apenas uma especificidade, que é o seu leitor: a criança ou o jovem. Mas como é literatura, dentro de todos os parâmetros da literatura, pode ser lida por qualquer idade. A diferença é que ela pode começar a ser lida na infância. Quando a LIJ tem qualidade estética, qualquer pessoa pode ler e se encantar. (2005: 148).

No mesmo passo, Maria Antonieta Antunes Cunha (1991), defende que a literatura infantil já está estabelecida e é mais abrangente, independente de seu adjetivo restritivo, podendo ser lida por qualquer pessoa, de qualquer idade. Faz, também, uma consideração interessante ao esclarecer que a literatura para adultos serve apenas para eles próprios, portanto, é mais restrita se comparada à literatura infantil.

Portanto, se literária, a literatura infanto-juvenil tem condições de ampliar seu público, tendo demanda das mais variadas idades e classes sócio-econômicas. A qualidade, o modo como são tecidas as tramas, a temática, a estimulação do imaginário, dentre outros pontos, são fundamentais numa obra para a criança e levam o adulto a revistar sua infância, rever situações e tirar conclusões de sua transição para o mundo da gente grande.

Há, no entanto, uma situação que distorceu a função da arte literária infantojuvenil: sua vinculação quase que restrita à pedagogia. Não se pode olvidar que juntas, literatura e prática pedagógica, exercem papel considerável na educação e na formação do leitor. Mas, devido a uma série de equívocos, a literatura voltada à infância esteve atrelada prioritariamente ao incentivo e à fomentação do gosto pela leitura, deixando de lado a qualidade e a grandiosidade intrínsecas às obras de arte como um todo. Assim, ela não era observada e estudada por si mesma, mas tão somente para sua aplicação escolar. Tanto é que dentro das Academias, nos cursos de Letras, a cadeira de literatura infanto-juvenil não é disciplina obrigatória, nem mesmo na licenciatura que tem por escopo a preparação adequada dos professores que irão ensinar a juventude nas escolas. 
Destarte, uma nova geração de críticos e estudiosos vem se ocupando com essa literatura tão preciosa quanto qualquer outra e que propicia o gosto pela leitura, entretanto, não se restringe somente a tal aspecto, tendo que ser encarada pela sua totalidade e por suas características literárias. Cientes de que a literatura infanto-juvenil é riquíssima, ao aprofundarem-se em seus caminhos, constatam que há muito o que se pesquisar e muitas obras para serem analisadas, debatidas, canonizadas ou excluídas do rol dos bons livros e autores consagrados.

As narrativas ficcionais de J. K. Rowling, nesse sentido, são classificadas como infanto-juvenis, devido aos elementos que as constituem e ao público leitor pretendido que as devora com voracidade, lendo e relendo-as várias vezes. Abrange, também, o campo da estética da recepção literária, visto que pessoas mais velhas podem se deliciar com as tramas bem amarradas da bruxa que criou Harry Potter.

\section{2) Fadas, Bruxas, Imaginário, Mitos, Lendas: O Fantástico na literatura infanto- juvenil}

Embora haja resistência e preconceito por parte da crítica, o gênero Fantástico está em voga novamente. Depois de anos esquecido, voltou à contemporaneidade trazido principalmente por intermédio do resgate feito pela literatura infanto-juvenil. Cabe lembrar aqui as significações do termo, no contexto genérico e não-literário, dentro de um dicionário da língua portuguesa. São eles: 1. Quimérico, fingido, que não tem realidade e só existe na imaginação; 2. Que pertence à fantasia; fantasioso, imaginativo; 3. Aparente, simulado, fictício; 4.Jactancioso; blasonador; 5. Caprichoso, exótico, extravagante; 6. O que só existe na imaginação. (in Dicionário Priberam da Língua Portuguesa, 2009).

A esse respeito, Tzetan Todorov, em Introdução à literatura fantástica (1977), define o Fantástico como "a hesitação experimentada por um ser que só conhece as leis naturais, face a um acontecimento aparentemente sobrenatural". No artigo " $O$ Sobrenatural no Fantástico" (2004), Cláudia Maria Xatara diz que a definição do Fantástico é variável de acordo com as obras que o delimitam e o exteriorizam, trazendo o seguinte posicionamento sobre o componente sobrenatural: 
Em literatura, pertence à categoria do sobrenatural todo texto cujo conteúdo fabular, além de não ter acontecido no plano histórico, não tem sequer a virtualidade do poder acontecer, porque infringe as leis físicas da realidade em que vivemos e os padrões normais da nossa razão. (2004:26).

Sem embargo, não adentraremos aqui nas implicações desse gênero propriamente ditas, nem nos desdobramentos do sobrenatural, mas sim, no âmago de sua relevância para a literatura infanto-juvenil: a fantasia nas obras infantis.

Os livros de Harry Potter são essencialmente fantásticos. Importa reconhecer que a autora criou um universo completamente estranho, revestido de uma ambientação épica, mas ao mesmo tempo reconhecível por aqueles que se detêm em suas páginas repletas de criaturas mágicas, feitiços, animais falantes, elfos, monstros, unicórnios, magos, bruxas, constituindo encantamentos que permeiam desde muito cedo o imaginário infantil.

A literatura fantástica vem gerando interesse no mundo inteiro. Ela funciona como uma transportadora ao subconsciente, criando mundos imaginários e paralelos ao mundo real. Jacqueline Held defende o seguinte ponto de vista:

Digamos apenas, em primeira abordagem, que pertencerá à literatura fantástica toda obra na qual temática, situação, atmosfera, mesmo linguagem, ou tudo isso junto, nos introduzirão num outro mundo que não o da percepção comum, diferente, estrangeiro, estranho, que nos permite voltar, pouco a pouco, ao longo da reflexão, a esses diferentes componentes. (1980:30).

$\mathrm{Na}$ infância o imaginário se faz presente desde o momento em que a criança consegue organizar seus pensamentos. Quando ela se descobre como pessoa, como um ser, ainda não faz completa distinção entre o que é real e o que não é, pois seu inconsciente não está sob o domínio da racionalidade. Um liame tênue entre realidade e imaginação circunda a vida do infante, que mistura os seus componentes e os aplica em sua existência. É possível constatar que o imaginário é uma mistura entre o real e a fantasia, traduzido em signos, e não é nem real nem ilusório, mas sim um intertexto decomposto dentro dessa dualidade fática.

A autora de Harry Potter quis fazer de suas aventuras um livro mágico, estranho e magnífico, construído especialmente para se parecer com o mundo real, e que, ao permitir que se leia a "céu aberto" no grande livro do mundo, assegura ao leitor a 
proteção contra as intempéries da vida real - e talvez até mesmo contra as intempéries de seu próprio psiquismo.

As narrativas voltadas ao público infanto-juvenil são representações paralelas da vida real, contendo lições de moral, sabedoria popular, conflitos de poder, formação de valores, dicotomia entre o bem e o mal e, consequentemente, mesclam fantasia e realidade em sua tecedura. Aqui encontra-se um ponto crucial dentro desse viés literário, qual seja, o subsídio oferecido ao leitor para que descubra coisas que não conseguiria alcançar sozinho. A relação das narrativas com nossa realidade torna-se algo consistente e não está exclusa das amarras sociais, pois é um simulador da existência. Portanto, o que faz da narrativa um texto tão interessante são seus acontecimentos atraentes e a mensagem que ela comunica à criança.

Tratando-se de mitologia, as estórias infantis estão recheadas delas. Os mitos estão presentes na história da humanidade, em todas as culturas, nos quatro cantos da Terra. Ao contrário do que se possa pensar hoje, eles não são uma inovação da literatura infanto-juvenil, e sim uma recriação, adaptação daqueles mitos que eram contados aos homens adultos milênios atrás. Tinham a função de utilizar o sagrado e o sobrenatural para explicar a nossa origem. Os mitos procuravam dar suporte a questões que são intrínsecas ao ser humano, como a espiritualidade, os sentimentos, a percepção do eu como pessoa, o motivo de sua existência, etc.

A mitologia, portanto, tem um lugar especial dentro da literatura infanto-juvenil, visto que permite ao jovem leitor deparar-se com criaturas, seres e situações inexistentes no mundo contemporâneo tão racionalista, coisas que não poderiam acontecer senão em uma outra esfera viva e real quanto a que os nossos olhos enxergam, chamada de imaginação. O mito exerce a sua função precípua que é a de transportar a criança ao seu inconsciente, ajudando-a a depreender o que se passa ao seu redor, facilitando seu processo de maturação psíquica.

O Fantástico não está desassociado da mitologia. Ambos se completam, se respaldam, são partes integrantes de suas respectivas composições. O contato com o mágico maravilhoso povoado de seres encantados, animais falantes, fadas, bruxas, centauros, unicórnios, lobisomens, mistérios variados, etc., soa como uma linguagem específica e familiar ao infante, que se identifica com as personagens e o auxilia a lidar com a dor, rejeição, abandono, morte, porquanto as crianças experimentam essas sensações e sentimentos na sua vida. Bruno Bettelheim, em seu livro A psicanálise dos contos de fadas, traz o seguinte posicionamento: 
A criança necessita muito particularmente que lhe sejam dadas sugestões em forma simbólica sobre a forma como ela pode lidar com estas questões e crescer a salvo para a maturidade. As estórias 'fora de perigo' não mencionam nem a morte nem o envelhecimento, os limites de nossa existência, nem o desejo pela vida eterna. (1980:14-15)

Durante o período em que o racionalismo podou boa parte da criatividade dos escritores, levando-os a crer que a metafísica e a espiritualidade eram elementos que atrasavam a evolução científica da humanidade, o gênero Fantástico foi esquecido, visto que já não era tido como satisfatório para o modelo da sociedade vigente. Tal atitude barrou o acesso às obras literárias de qualidade próprias para crianças, já que estas necessitavam adentrar o mundo adulto o quanto antes. Os livros infanto-juvenis não davam vazão ao imaginário, não utilizavam questões sentimentais e da vida cotidiana para amparar os tenros leitores na resolução de seus anseios, angústias, temores, não incentivavam a cidadania e mostravam personagens puramente bons ou maus que não existem de verdade. O maniqueísmo absoluto era muito frequente nas estórias infantojuvenis.

Por mais que seja difícil escrever para crianças num mundo em que a razão, a tecnologia e a cibernética preponderam, a literatura infanto-juvenil do século XXI vem efetuando o resgate do Fantástico e, por conseguinte, empregando lendas populares, contos de fadas, os mais variados mitos singulares e multiculturais, rompendo com o conceito de bem e mal genuíno (os heróis continuam bons, mas têm defeitos como qualquer ser humano de carne e osso), construindo e desconstruindo arquétipos, considerando o imaginário como terreno rico e fundamental na composição de suas narrativas, dentre outros requisitos indispensáveis. Nada mais interessante, fértil e salutar para crianças e jovens leitores. Os mundos encantados e recheados de fantasia e magia são locais familiares, e por isso, refletem os aspectos internos de cada um, a profundidade da nossa alma, funcionando como um espelho mágico na qual a criança se reconhece e na qual os conflitos psicológicos são problematizados e resolvidos por intermédio do viés literário. A série ficcional escrita por J. K. Rowling demonstra claramente que esse resgate é plausível, possível e necessário e que todos os elementos supramencionados reunidos oferecem um texto qualitativo para o público-alvo específico, a exemplo da saga Harry Potter.

\section{3) O fenômeno Harry Potter}


Harry Potter foi concebido durante uma viagem de trem de Manchester a Londres, Inglaterra, em 1990. Um estalo. O rosto do garoto surgiu juntamente com sua trajetória. A jovem professora não teve coragem de pedir aos passageiros papel e caneta para anotar os detalhes. Teve, então, que pensar neles durante as quatro horas de duração da viagem. É assim que a britânica Joanne Kathleen Rowling descreve o surgimento da ideia de escrever sobre o bruxinho que viria revolucionar a literatura infanto-juvenil mundial.

Joanne escreve desde criança. Aos seis anos escrevera seu primeiro "livro", contando as peripécias de um coelhinho chamado Coelho. Após a fama alcançada com os lançamentos dos livros da série potteriana, Rowling passou a dar entrevistas que permitiram aos leitores e fãs do menino mago conhecer um pouco da história de sua criadora. Cumpre frisar que na época em que escrevia as aventuras de Harry Potter à mão, ela dependia financeiramente do seguro-desemprego ofertado pelo governo inglês. Lecionou língua inglesa e Literatura numa escola em Portugal, onde morou algum tempo, devido à sua graduação em Letras-Francês na Universidade de Exeter, Inglaterra. Depois, retornou ao Reino Unido, indo instalar-se na Escócia, mais precisamente em Edimburgo. Somente em 1997, após algumas tentativas frustradas, conseguiu publicar seu livro Harry Potter e a Pedra Filosofal pela editora Bloomsbury. Foi justamente a referida editora que pediu que autora não usasse seu prenome por extenso, assinando o livro apenas com as iniciais daquele. Joanne escolheu então Kathleen, o nome de sua avó para compor sua nova e conhecida marca: J. K. Rowling. Foi a primeira jogada de marketing em torno da série colocada em prática, pois a Bloomsbury temia que os leitores do sexo masculino tivessem preconceito com um livro escrito por uma mulher.

O sucesso foi estrondoso. O "primogênito" da série recebeu alguns elogios, passando a figurar na lista dos livros mais vendidos. Nos anos de 1998, 1999 e 2000 foram lançados mais três títulos: Harry Potter e a Câmara Secreta, Harry Potter e o Prisioneiro de Azkaban e Harry Potter e o Cálice de Fogo, respectivamente. Em 2003, a escritora lançou o quinto livro da série, Harry Potter e a Ordem da Fênix. O sexto, Harry Potter e o Enigma do Príncipe, foi lançado em 2005 e, por último, Harry Potter e as Relíquias da Morte foi lançado simultaneamente no mesmo dia e horário no globo terrestre, em meados de 2007. Os números são assombrosos. Para se ter uma noção da dimensão do sucesso da série, o último livro isoladamente vendeu mais 44 milhões de exemplares até hoje, uma proeza fenomenal. Ao todo, a série completa já bateu a casa 
dos 400 milhões de livros vendidos mundialmente, segundo o sítio da internet Wikipédia.

Quando elaborou a trama mágica de Harry Potter, J. K. Rowling já tinha em mente que seriam sete volumes, um para cada ano do garoto na Escola de Magia e Bruxaria de Hogwarts. Segundo Nelly Novaes Coelho, no artigo O fenômeno Harry Potter e o nosso tempo em mutação, publicado num sítio da rede mundial de computadores, há influência na obra rowlinguiana das raízes histórico-fantásticas, tais como as celtas, escocesas, irlandesas, góticas, bretãs, povos que povoaram a Bretanha ao longo dos séculos e que se coadunaram na Idade Média, formando o Reino Unido que conhecemos hoje. Ainda segundo Coelho, há características nos livros de Rowling que permitem associá-los às obras do escritor escocês Walter Scott, romancista do século XIX, cujos enredos eram permeados pela fusão entre o real e o imaginário mágico-fantástico. Ângela Maria de Oliveira Lignani, em sua tese de doutorado defendida na Universidade Federal de Minas Gerais, diz que vários autores de língua inglesa influenciaram Joanne. Dentre elas, aponta as séries Os mundos de Crestomanci, da britânica Diane Wynne Jones, e As aventuras de Prydain, do norte-americano Lloyd Alexander, a obra $O$ Senhor dos Anéis, de J. R. R. Tolkien e o livro Tom Brown's School Days, de Thomas Huges, como também Lewis Carroll, autor de Alice no País das Maravilhas e Aventuras de Alice através do espelho. Figuram nesse rol ainda C. S. Lewis, William Shakespeare e John Milton.

Tem aumentado bastante o interesse pela série Harry Potter no meio acadêmico. Ao realizar incursões pela internet em busca de produções científicas acerca dela, num primeiro momento o internauta acredita que pouco encontrará no âmbito acadêmico brasileiro, por ser uma obra estrangeira. Contudo, logo em seguida, cai por terra essa impressão ao deparar-se com a quantidade de resultados em português do Brasil. Conforme citado acima, há tese de doutorado defendida em Universidade Federal (não só uma, mas várias e em outras faculdades de Universidades do país), dissertações de mestrado em Universidades públicas e particulares, projetos de pós-graduação, diversas monografias, artigos que citam e explicam Harry Potter como novo ícone da literatura infanto-juvenil, reportagens, dentre outros. Na monografia apresentada por Fernanda Alamino do Amaral, no curso de graduação em Comunicação da Universidade Federal da Bahia, 2005, a autora lança um olhar sobre a narrativa ficcional seriada de Harry Potter. Segundo ela, a série é bem sucedida no quesito entretenimento e traz um novo parâmetro para os contos de fadas. Na área de pós-graduação stricto sensu, em que pese a tese de Doutorado supracitada defendida na Universidade Federal de Minas Gerais por Ângela Maria de Oliveira Lignani, intitulada J. K. Rowling: Diálogo Literário e 
Cultural com Monteiro Lobato e Isabel Allende, no ano de 2007, a ora Doutora traça um diálogo cultural entre Joanne Kathleen Rowling, Monteiro Lobato e Isabel Allende, afirmando que a criadora de Harry Potter utiliza recursos empregados pelos dois outros escritores mencionados, como as lendas, a mitologia, o imaginário, estabelecendo, indubitavelmente, uma relação com a tradição literária mundial.

Continuando, ainda no mesmo artigo O fenômeno Harry Potter e o nosso tempo em mutação, Nelly Novaes Coelho discorre sobre as técnicas de mershandising em torno do lançamento dos livros, que deram impulso ainda maior para as vendas recordes mundial. Segundo a estudiosa, a série analisada foi o primeiro produto editorial voltado ao público infanto-juvenil que se tornou best-seller no mesmo nível de obras literárias “adultas". Um adendo interessante é que J. K. Rowling foi a primeira escritora a enriquecer vendendo seus escritos. Atualmente, sua fortuna é maior do que a da rainha da Inglaterra, estimada em quase 1 bilhão de dólares, provenientes da venda dos livros e produtos relacionados a série, como jogos de vídeo game, adaptações cinematográficas, materiais escolares, brinquedos, etc. Coelho ressalta que o sucesso de vendagem foi resultante de uma gigantesca engrenagem editorial "globalizada", movida a partir da Inglaterra e EUA, iniciando-se com a inteligente e complexa estratégia da tradução: cada volume é traduzido, com antecedência, em dezenas de idiomas para ser lançado simultaneamente em centenas de países e em tiragens que chegam a milhões de exemplares. Somem-se a isso as propagandas veiculadas nos meios de comunicação, os outdoors espalhados pelas cidades, as pré-vendas virtuais, as colunas de revistas e jornais que abordam o lançamento, o mistério que certamente faz parte do enredo, causador em boa dose da inquietação que leva os leitores a dormirem nas portas das livrarias no dia anterior ao lançamento, as crianças e adolescentes que se vestem com fantasias de bruxos, os concursos literários sobre o livro que será lançado, sem contar com os filmes que são campeões de bilheteria em todo o planeta, entre muitas outras estratégias marqueteiras da indústria cultural. Explica, ainda, que esse tipo de ação no Brasil é absoluta exceção, pois o processo adotado aqui é o do investimento direto das editoras nas escolas, junto aos professores, sem depender da intermediação das livrarias.

Está nítido que o enorme sucesso despertou o interesse dos estudiosos em descobrir o(s) seu(s) motivo(s). A criadora do bruxinho mais famoso do mundo "trouxa" (designação para quem não é bruxo) reuniu inúmeros fatores em suas páginas encantadas e chegou a um produto que inacreditavelmente superou grandes clássicos da literatura canônica. No entanto, a crítica, segundo Coelho, está dividida diante desse fenômeno sem precedentes. Há os que renegam o valor literário da série relegando-a estritamente ao campo da indústria cultural de massa, apenas pelo fato dela ter-se 
tornado best-seller e outros rejeitam a originalidade da linguagem criada por Rowling. O crítico americano Haroldo Bloom, considera a série uma "infindável sequência de clichês" e ressalta que "não é Alice no País dos Espelhos... é apenas ficção barata." (apud H.P. e a Filosofia). Já a crítica e romancista americana A. S. Byatt dispara num artigo publicado no New York Times que "o mundo mágico Rowling não tem espaço para o espiritual." (apud Caderno 2-OESP. 12.07.2003). Aqui, explicita Coelho, há controvérsias, considerando que o espiritual é uma das chaves para se entender a saga de Harry Potter.

Os vários debates sobre as causas do sucesso dos livros de J. K. Rowling pelo mundo afora e os estudos publicados demonstram que as narrativas da autora têm qualidade literária. Alguns encontros universitários como o Simpósio Harry Potter Nimbus 2003, realizado na Flórida e o Simpósio Nimbus 2004, ocorrido no Canadá, reuniram interessados a fim de analisar as tramas do mundo mágico de Harry Potter. Há, também, vários estudos já publicados como Harry Potter: as razões do Sucesso, de Isabelle Smadja, Harry Potter e a Filosofia, uma coletânea de ensaios coordenados por William Irwin, Almanaque de Harry Potter e outros bruxos, da editora Panda Books, Além da plataforma nove e meia, coletânea de ensaios múltiplos coordenada por Sissa Jacoby e Miguel Rettenmaier, Os segredos espirituais de Harry Potter, de Connie Neal, dentre outros. Tais ensaios discutem a fundo a obra ficcional de Rowling procurando e conseqüentemente encontrando características qualitativas que a elevam ao status literário.

Partindo do conteúdo explanado, não é possível afirmar com plena certeza que J. $\mathrm{K}$. Rowling pensou em escrever a série acreditando que se tornaria bilionária, visto que até então escritor algum conseguira tal feito, nem poderia prever que seu bruxinho se tornaria febre avassaladora, praticamente uma "pandemia", não só entre crianças e jovens, mas também entre adultos, que se curvaram diante do enredo tão bem costurado pela autora. Contudo, é razoável inferir que a escritora tinha em mente atingir grande número de pessoas ao prenunciar que viriam outros volumes complementares. A parte disso, o caráter transcendental da literatura infanto-juvenil em seus livros é visível: obras com público e tema definidos, mas que podem ser consumidas por todos os que quiserem lê-la e divagar através de suas linhas fantástico-maravilhosas.

\section{4) A trama mágica e sedutora do universo rowlinguiano}


Harry Tiago Potter é um garoto órfão de pai e mãe, assassinados por um bruxo das trevas chamado Voldemort, numa tentativa frustrada de matá-lo quando ainda era bebê. Harry cresceu longe do mundo da magia, fora criado por seus detestáveis tios "trouxas" e nunca soube a sua verdadeira identidade. Aos onze anos, recebeu uma carta convidando-o a estudar na Escola de Magia e Bruxaria de Hogwarts e fazer parte de um mundo mítico, repleto de seres encantados e desconhecidos, magia, poder, lendas. Para seu susto e felicidade, tomou conhecimento de que não pertencia àquele lugar que tanto o fizera sofrer desde novinho. A partir daí viveu intensas aventuras a cada livro, que corresponde sempre a um ano vivido pelo herói Potter e que prende a atenção dos leitores através de sua estruturação bem articulada.

A escolha desse universo mágico e sedutor não parece ter sido arbitrária. Poderia refletir o desejo de lançar um olhar mais liberto, embora também mais crítico sobre este nosso mundo que foi responsável pela caça às bruxas nos Estados Unidos, pela Inquisição na Idade Média e por todas as perseguições de que foram vítimas as pessoas acusadas de feitiçaria.

Crianças, como dito anteriormente, são seres que não fazem completa distinção entre o que é real e o que é imaginação, devido à sua inexperiência e à pouca maturação tanto psicológica, cerebral e fisiológica. Portanto, a literatura dedicada a elas deve se valer da fantasia, seres encantados, mitos, lendas, arquétipos, fadas, monstros, enfim, de uma gama de elementos que propiciam a criação de uma realidade mais prazerosa e que aguça o imaginário infantil. A ficção infanto-juvenil deve colocar o leitor defronte a problemas e situações adversas que ajudem-no a amadurecer para adentrar o tão conturbado mundo dos adultos no momento apropriado. As narrativas de Harry Potter fazem exatamente isso. Corroborando, Umberto Eco trata da questão ficcional afirmando que:

(...) qualquer passeio pelos mundos ficcionais tem a mesma função de um brinquedo infantil. As crianças brincam com boneca, cavalinho de madeira ou pipa a fim de se familiarizar com as leis físicas do universo e com os atos que realizarão um dia. Da mesma forma, ler ficção significa jogar um jogo através do qual damos sentido à infinidade de coisas que aconteceram, estão acontecendo ou vão acontecer no mundo real. Ao lermos uma narrativa, fugimos da ansiedade que nos assalta quando tentamos dizer algo de verdadeiro a respeito do mundo.

Essa é a função consoladora da narrativa - a razão pela qual as pessoas contam histórias e têm contado histórias desde o início dos tempos. E 
sempre foi a função suprema do mito: encontrar uma forma no tumulto da experiência humana. (2004:93)

Na mesma esteira, Bruno Bettelheim defende a seguinte posição:

$\mathrm{Na}$ verdade, em um nível manifesto, os contos de fadas ensinam pouco sobre as condições específicas da vida na moderna sociedade de massa; estes contos foram inventados muito antes que ela existisse. Mas através deles pode-se aprender mais sobre os problemas interiores dos seres humanos e sobre as soluções corretas para seus predicamentos em qualquer sociedade, do que com qualquer outro tipo de história dentro de uma compreensão infantil. (1980:13)

Harry Potter é um conto de fadas moderno. Vários elementos comprovam essa afirmação, como a morte prematura de seus pais, sua juventude tão cheia de mazelas e desgraças, sua criação por uma família odiosa que faz questão de demonstrar isso a todo o momento, o herói que descobre a felicidade fora do lugar em que sofreu a vida inteira, a perseguição promovida por um vilão que o odeia gratuitamente, a cicatriz em forma de raio adquirida após a tentativa de homicídio intentada contra ele quando era um bebê, são técnicas advindas dos contos de fadas muito bem tecidas e costuradas na trama mágica desenvolvida por Rowling na série Harry Potter.

Na concepção de Isabelle Smadja (2004), no livro Harry Potter, as razões do sucesso, Rowling utilizou-se das receitas próprias dos contos de fadas principalmente no primeiro livro da saga, que se mostra o mais doce e meigo de todos eles. O estudioso Marthe Robert (apud 1972) analisa a estrutura dos contos de fadas em Roman des origines et origines du Roman, informa:

Trata-se de provar, pelo exemplo de um herói sofredor, que inspira pena pela sua própria juventude - em geral é uma criança ou um adolescente, mais raramente um homem maduro -, que se pode ter um defeito físico, [...] ser malnascido, mal-amado, torturado com requinte por um ambiente inumano e, no entanto, ter acesso ao poder supremo pela virtude mágica do amor e de uma aliança com uma pessoa de alta posição. Para explicar o destino desse herói deserdado, que se desforra da vida com grande brilho, o conto realça um acidente de nascimento, que relaciona ou a um fenômeno natural, ou ao malefício de uma potência qualquer invisível. Muitas vezes, esse trauma é identificado com a morte da mãe. 
Cada leitor dessa saga, criança, jovem e, também, o adulto, gostaria de estudar em Hogwarts. O castelo, localizado no norte da Inglaterra, educa pequeninos, moças e rapazes há mais de mil anos. Foi fundado pelos quatro maiores bruxos da época. Eram eles: Godrico Gryffindor, Salazar Slytherin, Helga Hufflepuff e Rowena Ravenclaw. O ensino se restringe ao âmbito da magia, mas tem várias ramificações, como Transfiguração, Poções, Herbologia, Astronomia, História da Magia, a afamada Defesa contra as Artes das Trevas, dentre outras. A Escola é um local misterioso, possuindo poderosa magia em suas paredes e também em seu enorme terreno, com uma floresta e um lago para deixar mais atraente a sua figura imponente.

Ao longo de toda a obra, Rowling sustenta a ideia de que há um direito à desobediência quando as leis são injustas ou inadequadas. Ao mesmo tempo, ela própria se reserva o direito de libertar-se das regras da cronologia, misturando ostensivamente mitos, contos e lendas com fatos e épocas da história da humanidade.

Um aspecto bastante relevante no universo rowlinguiano é que não basta que a pessoa nasça bruxa, isto é, ser de família de bruxos ou ter um dos pais com essa condição, até porque gente completamente "trouxa" pode nascer com o dom. Para ser de fato um bruxo, é necessário que as crianças e adolescentes frequentem Hogwarts a fim de obterem a educação essencial e imprescindível à sua formação, com muitos deveres, lições práticas e teóricas, provas, testes, trabalhos, etc., tencionando o aprendizado da utilização e controle da magia. A Escola é um internato em que os alunos só voltam para casa no Natal e nas férias de verão. Interessante como os estudantes adoram o Colégio e não ficam tristes quando regressam, ao contrário, demonstram imensa felicidade e entusiasmo a cada retorno

Há uma divisão interna dentro de Hogwarts. Os alunos são selecionados por suas características e habilidades para se tornarem membros de uma das quatro Casas: Grifinória, Sonserina, Lufa-Lufa e Corvinal. Ainda que sejam separados por alojamentos distintos, o lema da Escola é a união entre seus estudantes. Com perspicácia, Rowling lança mão do artifício da rivalidade tão comum entre os adolescentes no âmbito escolar, contudo prega a igualdade nas diferenças para a construção de uma sociedade menos opressora.

O mundo bruxo é um lugar em que a tecnologia e as máquinas não existem, mas J. K. Rowling inventa inúmeros artefatos mágicos fascinantes para suprir essa "lacuna". Não há vídeo-games, carros, computadores, internet, aviões, caixas eletrônicos, robôs, nem nada do gênero. A autora desdenha dessa tecnologia dos "trouxas" sempre que pode, de um modo bastante sutil. Jovens e crianças bruxas gostam de vassouras voadoras, jogos de quadribol (esporte preferido dos bruxos de todo o mundo), animais 
falantes e criaturas mágicas, xadrez vivo, etc. A escritora tem o dom de articular o espírito de uma época e os desejos primitivos ou infantis da humanidade, por isso sua obra é um achado extraordinário.

Já fora explicitado que há um livro para cada ano do protagonista na Escola. Dessa maneira, J. K. Rowling pode esmiuçar os detalhes que rondam a agitada vida de Potter. Seus amigos Hermione Granger e Rony Weasley são seus companheiros fiéis. Há também a relação entre Harry e Alvo Dumbledore, com quem o garoto sempre conta para entender a fundo sua história. Dumbledore é o bruxo do bem mais poderoso ainda vivo, tanto que é o único de quem Lord Voldemort tem medo. A família de seu amigo Rony acolheu Harry em seu seio. A matriarca, Molly Weasley, trata o garoto como a um filho. O herói cresce, fica mais velho a cada livro, pois para que um estudante se forme em Hogwarts são necessários sete anos de estudos.

A personificação da sabedoria é o professor e diretor da Escola, Alvo Dumbledore. Ele procura incentivar os estudantes a enfrentarem seus temores e que encontrem as respostas sem auxílio demasiado. Afirma que é necessário ensinar a pescar e não entregar o peixe diretamente, pois assim o aluno cresce enquanto ser humano. Durante toda a trama ele se comporta dessa forma. Costuma ser enigmático e só explica os acontecimentos no final de cada volume. Esse tipo de atitude leva Harry e seus companheiros a procurarem a solução dos mistérios sozinhos e acabam ficando face a face com o perigo diversas vezes.

A questão da hierarquia institucional é assunto recorrente nos sete livros da série. O mundo bruxo tem um órgão governamental que regula o convívio dessa sociedade secreta. O Ministério da Magia é legislativo, executivo e judiciário ao mesmo tempo. Possui competência em todas as áreas que envolvem mágica e asseguram que os "trouxas" não descubram sua existência. J. K. Rowling demonstra que é necessário ter regras, leis, estatutos e outros instrumentos para regular a convivência conjunta pacificamente.

Apesar de ser uma ficção fantástica, a criadora de Harry Potter rejeita as superstições, optando pela razão nesse caso. Prova disso é que a disciplina Adivinhação é lecionada por uma professora charlatã, de aparência ridícula beirando a comicidade. Hermione Granger é quem derruba as teorias supersticiosas de seus amigos, abusando de sua inteligência e sagacidade para isso.

Já fora explicitado que há um livro para cada ano do protagonista na Escola. Dessa maneira, J. K. Rowling pode esmiuçar os detalhes que rondam a agitada vida de Potter. Seus amigos Hermione Granger e Rony Weasley são seus companheiros fiéis. Há também a relação entre Harry e Alvo Dumbledore, com quem o garoto sempre conta 
para entender sua história profundamente. Dumbledore é o bruxo do bem mais poderoso ainda vivo, tanto que é o único de quem Lord Voldemort tem medo. A família de seu amigo Rony acolheu Harry em seu seio. A matriarca, Molly Weasley, trata o herói como a um filho. O garoto cresce, fica mais velho a casa livro, pois para que um estudante se forme em Hogwarts são necessários sete anos de estudos e a autora premeditou essa sequência.

O emocional é um elemento bem trabalhado na saga. O protagonista é um herói típico, mas não se enquadra no padrão "bonzinho" e "puro". Harry é um garoto com desejos, emoções, vontades, medos. Sente raiva, tem ataques de fúria, se apaixona, se frustra, se decepciona e decepciona as pessoas, além de ter ótimas qualidades, como a bravura e a lealdade. O tema morte é discutido todo o tempo, a começar pelo óbito de seus pais e tantas outros ocorridos durante a série. Pessoas caras a Harry e aos leitores morrem na trajetória potteriana sem o mínimo constrangimento por parte da autora. Desse modo, Rowling suscita o espiritualismo, pondo o leitor defronte com essa situação triste, mas inevitável, ajudando-o a compreender esse processo.

Vivemos numa era em que os valores estão banalizados e os jovens se encontram aprisionados pelas exterioridades do mundo do espetáculo. Não há mais espaço para a reflexão, para o ser interior, para o pensar. J. K. Rowling põe em evidência a solidariedade, a amizade, os bons sentimentos, e insiste na tese de que o amor motivado e cultivado é a arma mais poderosa contra as opressões causadas por tiranos como o Lord das Trevas, Voldemort.

De acordo com Nelly Novaes Coelho, no artigo citado no tópico anterior, Harry Potter é o porta-voz do novo homem do século XXI, ainda em gestação. Afirma que os elementos de que são feitos os sete livros são arquétipos, modelos de pensamentos e ação, preexistentes na alma humana, ou seja, são estruturas psíquicas praticamente universais. Simbolicamente, essas histórias arcaicas apontam para o processo de amadurecimento interior, pelo qual o ser humano deve passar para revelar sua verdadeira personalidade. Ela prossegue insistindo que, o universo rowlinguiano, formado pelo mundo dos bruxos e pelo mundo dos "trouxas", pode ser lido como uma grande e fantástica alegoria do mundo ocidental e sua organização sócio-políticoeconômica, hoje em pleno processo de mutação, com sua lógica, fundamentos liberais, suas certezas absolutas, desafiados pelo mistério de um mundo ao qual a ciência usurpou seu centro sagrado (Deus), mas não conseguiu explicar o mistério da vida e do homem.

Harry Potter é uma alegoria desse homem moderno. Sua trama tem forte ligação com as lendas célticas e nórdicas e contém rica mitolgia. É um inteligente amálgama de 
heranças dos tempos primordiais (mitos, arquétipos, processos de iniciação do saber oculto, processos de magia, mistérios da alquimia), fundidas dados reais do nosso mundo contemporâneo. A série ora analisada é uma obra prima de construção literária, pela arte da escrita de J. K. Rowling, que é dona de uma imaginação incomum, original e complexa. Os acontecimentos que são descritos ininterruptamente criam intimidade com o leitor, arrastando-o num ritmo acelerado. Esse ritmo empreendido pela autora nos lembra a velocidade generalizada da globalização, já tão arraigada pelos jovens e adultos de hoje.

Apesar de a série ser formada por sete volumes, cada um deles pode ser lido independentemente. O leitor não necessita ler os outros para compreender a trama de um deles especificamente, visto que Rowling costura e constrói habilmente as aventuras do herói. Por isso, a leitura da série pode começar por qualquer dos volumes e o essencial será perfeitamente conhecido e compreendido.

Harry Potter não é uma leitura vazia; ao contrário, revela-se rica por seus mínimos detalhes narrados, a composição de suas personagens, os temas abordados, a valorização dos bons sentimentos, que atualmente estão em desuso, o assunto das instituições hierárquicas, as leis injustas e o poder desmesurado como motivação para a desmoralização, corrupção, ganância e conflitos éticos.

A coerência de seus escritos realiza um dos grandes sonhos do nosso tempo: reencontrar, para além da fragmentação dos pensamentos e das teorias, um saber enciclopédico perdido e mergulhar de novo em uma época na qual ainda se podiam conciliar os conhecimentos.

A série caiu nas graças da mídia e virou sensação mundial graças ao seu universo mágico-fantástico e seus elementos intrínsecos, haja visto que Harry Potter é uma obra para a juventude, porque o mundo da bruxaria é a metáfora do mundo da infância em face do mundo adulto. A pós-modernidade impõe uma forma diferenciada de viver a realidade prática do dia-a-dia, que interfere na vivência psíquica de nossa existência e esse tipo de literatura veio suprir carências espirituais e psicológicas da humanidade. Não se trata de um simples produto da indústria cultural, mas sim de um texto infanto-juvenil autêntico e articulado com perfeição pela arte de J. K. Rowling.

\section{Referências bibliográficas.}

BETTELHEIM, Bruno. A psicanálise dos contos de fadas. São Paulo: Paz e Terra, 1980. 
COELHO, Nelly Novaes. Literatura infantil: Teoria - Análise - Didática. São Paulo: Moderna, 2000.

CUNHA, Maria Antonieta Antunes. Literatura Infantil - Teoria e Prática. São Paulo: Ática, 1991.

ECO, Umberto. Seis passeios pelos bosques da ficção. São Paulo: Companhia das letras, 1994.

. Sobre a Literatura. 2 ed. Rio de Janeiro: Record, 2004.

FERNANDES, Dirce Lorimier. A literatura Infantil. São Paulo: Edições Loyola, 2003.

HELD, Jacqueline. O imaginário no poder: as crianças e a literatura fantástica. São Paulo: Summus, 1980.

IRWIN, William. Harry Potter e a Filosofia. São Paulo: Madras, 2004.

QUEIRÓS, Bartolomeu Campos de. "Leitura, um diálogo subjetivo". In: OLIVEIRA, Ieda de. $O$ que é qualidade em literatura infantil e juvenil?: com a palavra, o escritor. São Paulo: DCL, 2005, p. 167-174.

RAMOS, Anna Cláudia. "Ojogo do faz-de-conta”. In: OLIVEIRA, Ieda de. O que é qualidade em literatura infantil e juvenil?: com a palavra, o escritor. São Paulo: DCL, 2005, p. 147-166.

ROBERT, Marthe. Roman des origenes et origines du Roman. Paris: Gallimard, 1972.

ROWLING, Joanne Kathleen. Harry Potter e a Pedra Filosofal. Rio de Janeiro: Rocco, 2000 .

. Harry Potter e a Câmara Secreta. Rio de Janeiro: Rocco, 2000.

. Harry Potter e o Prisioneiro de Azkaban. Rio de Janeiro: Rocco, 2000.

. Harry Potter e o Cálice de Fogo. Rio de Janeiro: Rocco, 2001.

. Harry Potter e a Ordem da Fênix. Rio de Janeiro: Rocco, 2003.

Harry Potter e o Enigma do Príncipe. Rio de Janeiro: Rocco, 2005.

Harry Potter e as Relíquias da Morte. Rio de Janeiro: Rocco, 2007.

SMADJA, Isabelle. Harry Potter - as razões do sucesso. Rio de Janeiro: Contraponto, 2004.

TODOROV, Tzvetan. Introdução à Literatura Fantástica. São Paulo: Moraes, 1977.

XATARA, Cláudia Maria. O sobrenatural no fantástico. Uberlândia: Revista Letras \& Letras, 2004.

ZILBERMAN, Regina. A literatura infantil na escola. São Paulo: Global, 2003.

http://www.pucsp.br/revistafronteiraz/download/pdf/tensao.pdf - Acesso em: 26/08/2009.

A tensão entre o Fantástico e o Maravilhoso - Maria Romero Marçal.

http://www.filologia.org.br/soletras/10/11.htm - Acesso em: 17/09/2009.

Dos Fantásticos ao Fantástico: Um percurso pelas teorias do Gênero - Flávio Garcia e Angélica Maria Santana Batista.

http://www.unicamp.br/iel/site/alunos/publicacoes/textos/f00002.htm - Acesso em: 17/09/2009.

O Fantástico e a Fantasia - Jefferson Vasques Rodrigues.

http://www.hildahilst.com.br/separata.php?categoria=10\&id=31 - Acesso em: $31 / 08 / 2009$.

O fenômeno Harry Potter e o nosso tempo em mutação - Nelly Novaes Coelho.

http://francinemacieldealmeida.googlepages.com/tccfrancinealmeida.pdf - Acesso em: 13/09/2009.

Harry Potter no Orkut: formando leitores adolescentes - Francine Maciel de Almeida. http://www.facom.ufba.br/pex/2005 1/fernandaalamino.pdf - Acesso em: 22/09/2009. 
Narrativas Ficcionais Seriadas: um estudo sobre Harry Potter - Fernanda Alamino do Amaral.

http://www.alb.com.br/anais16/sem03pdf/sm03ss08 03.pdf - Acesso em: 13/09/2009.

Identidades juvenis e de gênero nas narrativas (mágicas) sobre Harry Potter - Fabiana de Brito Pires; Maria Lúcia Castagna Wortmann e Isabel Christina Zoppas.

http://www.pucrs.br/edipucrs/online/IIImostra/Letras/61859\%20-\%20ANA \%20CLAUDIA $\% 20$ MUNARI\%20DOMINGOS\%20PELISOLI.pdf - Acesso em: 22/09/2009.

Harry Potter: um chamado ao leitor - Ana Cláudia Munari Domingos Pelisoli http://www.intercom.org.br/papers/nacionais/2007/resumos/R1063-1.pdf - Acesso em: 28/09/2009.

Harry Potter: Conexões Midiáticas, Produção e Circulação, Cenários Urbanos e Juvenis - Silvia Helena Simões Borelli.

http://dspace.lcc.ufmg.br/dspace/bitstream/1843/ECAP-

6ZGFM9/1/tese vers o pdf.pdf - Acesso em: 17/09/2009.

J. K. Rowling: Diálogo Literário e Cultural com Monteiro Lobato e Isabel Allende Ângela Maria de Oliveira Lignani.

http://www.dialogarts.uerj.br/casepel/CaSePEL 3.pdf\#page $=7$

Casepel - Cadernos do Seminário Permanente de Estudos Literários.

http://super.abril.com.br/cultura/bruxa-criou-harry-potter-445103.shtml - Acesso em 02/09/2009.

A bruxa que criou Harry Potter - Joana Monteleone e Heraldo Ceravolo Sereza.

http://pt.wikipedia.org/wiki/Harry_Potter_s\%C3\%A9rie) Acesso em 12/10/2009.

Série Harry Potter.

http://prosamagica.blogspot.com/2009/08/etica-e-moral-em-jkrowling.html - Acesso em: 23/08/2009.

Ética e Moral em J. K. Rowling - Soraya Felix.

http://www.priberam.pt/ - Acesso em: 28/09/2009

Dicionário Priberam da Língua Portuguesa. 
